Check for updates

Cite this: RSC Adv., 2017, 7, 17934

\title{
A series of lanthanide glutarates: lanthanide contraction effect on crystal frameworks of lanthanide glutarates $\uparrow$
}

\author{
Xiao-Feng Tan, ${ }^{a}$ Jian Zhou, (D) *a Hua-Hong Zou, ${ }^{\text {*b }}$ Lianshe Fu, $^{\text {*c }}$ Qiuling Tang ${ }^{a}$ \\ and Peng Wang ${ }^{a}$
}

A series of lanthanide glutarates $\left[\mathrm{Ln}(\text { phen) }(\mathrm{glu}) \mathrm{Cl}]_{n}\{\mathrm{Ln}=\mathrm{Y}(1 \mathrm{a}), \mathrm{Tm}(1 \mathrm{~b})\right.$; phen =1,10-phenanthroline; glu $=$ glutarate $\},\left[\mathrm{Ln}_{2}(\text { phen })_{2}(\mathrm{glu})_{3}\right]_{n}\{\mathrm{Ln}=\mathrm{Ce}(2 \mathrm{a}), \mathrm{Tb}(2 \mathrm{~b}), \mathrm{Ho}(2 \mathrm{c})\}$ and $\left[\mathrm{La}_{2}(\mathrm{glu})_{3}\left(\mathrm{H}_{2} \mathrm{O}\right)_{3}\right]_{n} \cdot 5 n \mathrm{H}_{2} \mathrm{O}(3)$ have been hydrothermally synthesized and characterized structurally. Compounds $1 a-b$ are isostructural and consist of 1-D neutral $[\mathrm{Ln}(\mathrm{phen})(\mathrm{glu}) \mathrm{Cl}]_{n}$ chains, which are built up from the linkages of [ $\mathrm{Ln}(\text { phen } \mathrm{Cl}]^{3+}$ ions and glutarate ligands. Compounds $2 \mathrm{a}-\mathrm{c}$ are isostructural and contain 2-D $\left[\mathrm{Ln}_{2}(\text { phen })_{2}(\mathrm{glu})_{3}\right]_{n}$ layers, where $\mathrm{Ln}^{3+}$ ions are connected by three kinds of glutarate ligands. The 3-D framework of compound 3 is constructed by the linkages of $\mathrm{La}^{3+}$ ions and glutarate ligands. Although some 3-D lanthanide glutarates have been reported, they exhibit a very robust structural type, whose structure is not changed by different $\mathrm{Ln}^{3+}$ ions, but compound 3 shows a new structural type. A systematic investigation of six lanthanide glutarates and some reported compounds revealed that the well-known lanthanide contraction has a significant influence on the formation of lanthanide glutarates. The photoluminescent properties of $1 \mathrm{~b}$ and $2 \mathrm{~b}$, and magnetic properties of $1 \mathrm{~b}$, $2 \mathrm{~b}$ and $2 \mathrm{c}$ have been studied.

Received 7th February 2017
Accepted 15th March 2017

DOI: 10.1039/c7ra01552f

rsc.li/rsc-advances
$\mathrm{O}-\mathrm{H}, \mathrm{N}-\mathrm{H}$ and $\mathrm{C}-\mathrm{H}$ oscillators that tend to quench photoluminescence, ${ }^{4}$ the other is to promote the antenna effect, which pumps up $\mathrm{Ln}^{3+}$ emission by using $\pi$-conjugated organic aromatic chromophores directly coordinated to $\mathrm{Ln}^{3+}$ ions. ${ }^{5}$ Bidentate neutral 1,10-phenanthroline (phen) is one of the widest used chromophoric ligand in the design of photoluminescent lanthanide complexes, because it can chelate to $\mathrm{Ln}^{3+}$ ion, which may not only encapsulate and protect the $\mathrm{Ln}^{3+}$ ion from the water molecules, but also absorb and efficiently transfer energy onto the $\mathrm{Ln}^{3+}$ excited states. As expected, a large number of photoluminescent Ln-complexes containing neutral phen and its derivatives have been synthesized, ${ }^{6}$ but their solids are difficult to directly use as photoluminescent sources, mainly because phen or its derivatives acting as terminating group prevent further connections, resulting in molecules that show poor thermal stability, weak moisture stability and feeble mechanical strength.

Glutaric acid is one of excellent long-chain aliphatic dicarboxylic acids with flexible bridging capability for the construction of a diversity of lanthanide coordination polymers. ${ }^{7}$ But water molecule is easily bound to $\mathrm{Ln}^{3+}$ ion in the absence of chelating chromophoric ligand, which could lead to efficient nonradiative deactivation of their excited states. It is expected that phen or its derivatives in conjunction with glutaric acid may generate a new class of lanthanide coordination polymers with enhanced thermal stability, high luminescence quantum yield and relatively long-lived emission. However, a few 
lanthanide glutarates containing phen or its derivatives were prepared under certain synthetic conditions, ${ }^{8}$ where the significant influence of lanthanide contraction on their structures and the relationship between the structures and photoluminescent properties have been rarely reported to the best of our knowledge. To further explore the influences on the formation of lanthanide glutarates, it is necessary to synthesize a series of new lanthanide glutarates for improving their desirable photoluminescent properties. This paper reports the synthesis, crystal structures and properties of a series of new lanthanide glutarates $[\operatorname{Ln}(\text { phen })(\text { glu }) \mathrm{Cl}]_{n}\{\operatorname{Ln}=\mathrm{Y}(\mathbf{1 a}), \operatorname{Tm}(\mathbf{1 b})\}$, $\left[\operatorname{Ln}_{2}(\text { phen })_{2}(\mathrm{glu})_{3}\right]_{n}\{\mathrm{Ln}=\mathrm{Ce}(\mathbf{2 a}), \mathrm{Tb}(\mathbf{2 b})$, Ho (2c) $\}$ and $\left[\mathrm{La}_{2}(-\right.$ glu $\left.)_{3}\left(\mathrm{H}_{2} \mathrm{O}\right)_{3}\right]_{n} \cdot 5 n \mathrm{H}_{2} \mathrm{O}$ (3). A systematic investigation of six lanthanide glutarates and some reported compounds exhibited that the well-known lanthanide contraction has a significant influence on the formation of lanthanide glutarates.

\section{Experimental}

\section{General remarks}

All analytical grade chemicals were obtained commercially and used without further purification. IR spectra were obtained from a powdered sample pelletized with $\mathrm{KBr}$ on an $\mathrm{ABB}$ Bomen MB 102 series IR spectrophotometer in the range of 400-4000 $\mathrm{cm}^{-1}$. Elemental analyses $(\mathrm{C}, \mathrm{H}, \mathrm{N})$ were performed on an Elemental Vario EL III analyzer. The photoluminescence spectra were recorded at room temperature with a modular double grating excitation spectrofluorimeter with a TRIAX 320 emission monochromator (Fluorolog-3, Horiba Scientific) coupled to an R928 Hamamatsu photomultiplier. The excitation source was a $450 \mathrm{~W}$ Xe arc lamp. The emission spectra were corrected for detection and optical spectral response of the spectrofluorimeter and the excitation spectra were corrected for the spectral distribution of the lamp intensity using a photodiode reference detector. Variable-temperature magnetic susceptibility measurements were carried out in the temperature range of 2-300 K with a Quantum Design MPMS-5 magnetometer. Thermogravimetric analyses (TGA) were performed using a Mettler TGA/SDTA851 thermal analyzer under an air-flow atmosphere with a heating rate of $10{ }^{\circ} \mathrm{C} \mathrm{min}^{-1}$ in the temperature region of $25-600{ }^{\circ} \mathrm{C}$.

\section{Synthesis of $\mathrm{Y}($ phen $)($ glu $) \mathrm{Cl}]_{\boldsymbol{n}}$ (1a)}

A mixture of glutaric acid $(0.0264 \mathrm{~g}, 0.20 \mathrm{mmol})$, phen $(0.0270 \mathrm{~g}$, $0.15 \mathrm{mmol}), \mathrm{YCl}_{3}(0.0742 \mathrm{~g}, 0.38 \mathrm{mmol})$, and water $(2 \mathrm{~mL})$ was stirred for $1 \mathrm{~h}$, and then the $\mathrm{pH}$ value of the mixed solution was adjusted to $5-6$ by triethylamine. The final mixture was sealed in a $25 \mathrm{~mL}$ Teflon lined autoclave and heated at $100{ }^{\circ} \mathrm{C}$ for 7 days. After cooling to room temperature slowly, colorless block crystals were isolated. The yield of $\mathbf{1 a}$ is $73 \%$ based on $\mathrm{YCl}_{3}$. Anal. calcd for 1a, $\mathrm{C}_{17} \mathrm{H}_{14} \mathrm{ClN}_{2} \mathrm{O}_{4} \mathrm{Y}, \mathrm{C} 46.98 \%, \mathrm{H} 3.25 \%, \mathrm{~N}$ 6.44\%, found: C 47.12\%, H 3.28\%, N 6.47\%. IR ( $\left.\mathrm{cm}^{-1}\right): 3094(\mathrm{w})$, 3054(w), 2900(w), 1598(s), 1517(w), 1420(s), 1350(m), 1280(m), 1219(m), 1169(m), 1099(m), 1059(m), 934(vw), 859(s), 817(m), 781(m), 727(s), 650(m), 539(w).

\section{Synthesis of $\mathrm{Tm}($ phen$)(\mathrm{glu}) \mathrm{Cl}]_{n}(1 \mathrm{~b})$}

The colorless crystals of $\mathbf{1 b}$ were prepared similarly from $\mathrm{TmCl}_{3}$ (yield $63 \%$ based on $\mathrm{TmCl}_{3}$ ). Anal. calcd for $\mathbf{1 b}, \mathrm{C}_{17} \mathrm{H}_{14} \mathrm{ClN}_{2} \mathrm{O}_{4}$ Tm, C 39.67\%, H 2.74\%, N 5.44\%, found: C 39.63\%, H 2.76\%, N 5.46\%. IR ( $\left.\mathrm{cm}^{-1}\right): 3094(\mathrm{w}), 3054(\mathrm{w}), 2900(\mathrm{w}), 1591(\mathrm{vs}), 1517(\mathrm{w})$, 1467(w), 1413(s), 1350(m), 1280(m), 1212(m), 1156(m), 1106(m), 1052(m), 962(vw), 851(s), 817(m), 781(m), 727(s), 664(m), $540(\mathrm{w})$.

\section{Synthesis of $\left[\mathrm{Ce}_{2}(\text { phen })_{2}(\mathrm{glu})_{3}\right]_{n}(2 \mathrm{a})$}

The yellow crystals of $\mathbf{2 a}$ were prepared similarly from $\mathrm{CeCl}_{3}$ (yield $78 \%$ based on $\mathrm{CeCl}_{3}$ ). Anal. calcd for $2 \mathrm{a}, \mathrm{C}_{39} \mathrm{H}_{34} \mathrm{Ce}_{2} \mathrm{~N}_{4} \mathrm{O}_{12}$, C $45.44 \%, \mathrm{H} 3.32 \%, \mathrm{~N} 5.43 \%$, found: C $45.46 \%, \mathrm{H} 3.34 \%, \mathrm{~N}$ 5.47\%. IR ( $\left.\mathrm{cm}^{-1}\right): 3081(\mathrm{w}), 3040(\mathrm{w}), 2923(\mathrm{w}), 1598(\mathrm{vs}), 1524(\mathrm{~s})$, 1426(s), 1343(m), 1316(s), 1266(m), 1142(m), 1106(m), 1059(m), 857(s), 794(s), 734(s), 677(w), 636(m), 519(m).

\section{Synthesis of $\left[\mathrm{Tb}_{2}(\text { phen })_{2}(\text { glu })_{3}\right]_{n}(2 \mathrm{~b})$}

The brown crystals of $\mathbf{2 b}$ were prepared similarly from $\mathrm{TbCl}_{3}$ (yield $73 \%$ based on $\mathrm{TbCl}_{3}$ ). Anal. calcd for $2 \mathbf{b}, \mathrm{C}_{39} \mathrm{H}_{34} \mathrm{~N}_{4} \mathrm{O}_{12} \mathrm{~Tb}_{2}$, C $43.84 \%$, H 3.21\%, N 5.24\%, found: C 43.86\%, H $3.23 \%, \mathrm{~N}$ 5.28\%. IR (cm $\left.{ }^{-1}\right): 3013(\mathrm{w}), 2894(\mathrm{w}), 1544(\mathrm{~s}), 1454(\mathrm{~s}), 1413(\mathrm{~s})$, 1350(m), 1280(m), 1219(m), 1183(w), 1065(m), 1009(w), 934(w), 885(m), 824(m), 740(s), 664(m), 520(m).

\section{Synthesis of $\left[\mathrm{Ho}_{2}(\text { phen })_{2}(\text { glu })_{3}\right]_{n}(2 \mathrm{c})$}

The red crystals of $2 \mathrm{c}$ were prepared similarly from $\mathrm{HoCl}_{3}$ (yield $83 \%$ based on $\mathrm{HoCl}_{3}$ ). Anal. calcd for $2 \mathrm{c}, \mathrm{C}_{39} \mathrm{H}_{34} \mathrm{Ho}_{2} \mathrm{~N}_{4} \mathrm{O}_{12}, \mathrm{C}$ $43.35 \%, \mathrm{H} 3.17 \%, \mathrm{~N} 5.18 \%$, found: C $43.37 \%, \mathrm{H} 3.19 \%, \mathrm{~N}$ 5.21\%. IR ( $\left.\mathrm{cm}^{-1}\right)$ : 3094(w), 3047(w), 2930(w), 1627(s), 1551(s), $1440(\mathrm{~s}), \quad 1350(\mathrm{~m}), \quad 1316(\mathrm{~m}), \quad 1266(\mathrm{~m}), \quad 1149(\mathrm{~m}), \quad 1106(\mathrm{~m})$, 1065(m), 851(s), 808(m), 734(s), 670(w), 643(m), 536(m).

\section{Synthesis of $\left[\mathrm{La}_{2}(\mathrm{glu})_{3}\left(\mathrm{H}_{2} \mathrm{O}\right)_{3}\right]_{n} \cdot 5 n \mathrm{H}_{2} \mathrm{O}$ (3)}

The colorless crystals of 3 were prepared similarly from $\mathrm{La}_{2} \mathrm{Cl}_{3}$ (yield $67 \%$ based on $\mathrm{La}_{2} \mathrm{Cl}_{3}$ ). Anal. calcd for $3, \mathrm{C}_{15} \mathrm{H}_{34} \mathrm{La}_{2} \mathrm{O}_{20}, \mathrm{C}$ $22.18 \%, \mathrm{H} 4.22 \%$, found: $\mathrm{C} 22.23 \%, \mathrm{H} 4.27 \%$. IR $\left(\mathrm{cm}^{-1}\right)$ : 3435(s), 2950(w), 1551(s), 1440(s), 1323(m), 1259(m), 1169(w), 1072(w), 968(m), 885(m), 801(w), 657(m), 546(m).

\section{X-ray crystallography}

Single-crystal X-ray diffraction data for all compounds were collected on a Rigaku Mercury CCD diffractometer using a $\omega$ scan method with graphite monochromated Mo $\mathrm{K} \alpha$ radiation $(\lambda=0.71073 \AA$ A). Routine Lorentz polarization and absorption corrections were applied using multi-scan technique. The structures of all compounds were solved by direct methods of SHELXS-97 (ref. 9) and refined by full-matrix least-squares methods on $\mathrm{F}^{2}$ using the SHELXL-97 program package. ${ }^{10}$ Positions of $\mathrm{H}$ atoms from phen and glu ligands were geometrically placed and $\mathrm{H}$ atoms were refined isotropically as a riding mode using the default SHELXTL parameters. A summary of crystallographic data is listed in Table 1.1528897- 
Table 1 Crystallographic data for all compounds

\begin{tabular}{|c|c|c|c|c|c|c|}
\hline & 1a & $1 b$ & $2 \mathbf{a}$ & $2 \mathbf{b}$ & $2 c$ & 3 \\
\hline Formula & $\mathrm{C}_{17} \mathrm{H}_{14} \mathrm{ClN}_{2} \mathrm{O}_{4} \mathrm{Y}$ & $\mathrm{C}_{17} \mathrm{H}_{14} \mathrm{Cl} \mathrm{N} \mathrm{O}_{4} \mathrm{Tm}$ & $\mathrm{C}_{39} \mathrm{H}_{34} \mathrm{Ce}_{2} \mathrm{~N}_{4} \mathrm{O}_{12}$ & $\mathrm{C}_{39} \mathrm{H}_{34} \mathrm{~N}_{4} \mathrm{O}_{12} \mathrm{~Tb}_{2}$ & $\mathrm{C}_{39} \mathrm{H}_{34} \mathrm{Ho}_{2} \mathrm{~N}_{4} \mathrm{O}_{12}$ & $\mathrm{C}_{15} \mathrm{H}_{34} \mathrm{La}_{2} \mathrm{O}_{20}$ \\
\hline$F_{\mathrm{w}}$ & 434.66 & 514.68 & 1030.94 & 1068.56 & 1080.56 & 812.24 \\
\hline Crystal system & Monoclinic & Monoclinic & Triclinic & Triclinic & Triclinic & Triclinic \\
\hline$a, \AA$ & $8.1640(4)$ & $8.1381(11)$ & $8.8586(18)$ & $8.7895(4)$ & $8.7671(5)$ & $9.076(2)$ \\
\hline$b, \AA$ & $12.4878(6)$ & $12.4629(16)$ & $13.565(3)$ & $13.4391(7)$ & $13.4002(7)$ & $9.867(3)$ \\
\hline$c, \AA$ & $16.1848(8)$ & $16.161(3)$ & $16.392(3)$ & $16.4098(9)$ & $16.4124(11)$ & $16.303(4)$ \\
\hline$\gamma$, deg & 90 & 90 & $75.14(3)$ & $74.984(2)$ & $75.048(2)$ & $98.526(10)$ \\
\hline$V, \AA^{3}$ & $1646.00(14)$ & $1635.1(4)$ & $1887.2(7)$ & $1856.50(16)$ & 1847.46(19) & $1345.0(6)$ \\
\hline$Z$ & 4 & 4 & 2 & 2 & 2 & 2 \\
\hline$T, \mathrm{~K}$ & $293(2)$ & $297(2)$ & $293(2)$ & $300(2)$ & $297(2)$ & $293(2)$ \\
\hline Calcd density, $\mathrm{Mg} \mathrm{m}^{-3}$ & 1.754 & 2.092 & 1.814 & 1.912 & 1.942 & 2.006 \\
\hline$F(000)$ & 872 & 992 & 1016 & 1044 & 1052 & 796 \\
\hline $\mathrm{w} R_{2}$ (all data) & 0.1311 & 0.0719 & 0.0582 & 0.0561 & 0.0532 & 0.0791 \\
\hline
\end{tabular}

1528902 contains the supplementary crystallographic data for this paper. $\dagger$

\section{Results and discussion}

\section{Crystal structure}

Description of $\left[\operatorname{Ln}(\right.$ phen $)(\text { glu)Cl }]_{n}[\operatorname{Ln}=$ Y (1a), Tm (1b)]. Both 1a and $\mathbf{1 b}$ are isostructural, so only $\mathbf{1 a}$ is discussed here in detail. 1a crystallizes in the monoclinic space group $P 2_{1} / n$ with four formula units in the unit cell. The asymmetric unit contains one $\mathrm{Y}^{3+}$ ion, one glu ligands and one phen ligand (Fig. S1 $\uparrow$ ). The coordination geometry of $\mathrm{Y}^{3+}$ ions is a distorted triangular dodecahedron comprised of five $\mathrm{O}$ atoms from four glu ligands, two $\mathrm{N}$ atoms of one chelating phen ligand and one $\mathrm{Cl}^{-}$ion. The $\mathrm{Y}-\mathrm{O} / \mathrm{N}$ bond distances vary from $2.270(4)$ to $2.550(4) \AA$, and the $\mathrm{Y}-\mathrm{Cl}$ bond length is 2.6287(15) $\AA$, which are in agreement with corresponding values in other $\mathrm{Y}^{3+}$ complexes. ${ }^{11}$ The glu ligand with an anti-gauche conformation adopts chelating/bridging tridentate and bridging bidentate mode, which are connected with $\mathrm{Y}^{3+}$ ions to form 1-D chain (Fig. 1a). Phen ligands are regularly appended to both sides of the chain. These chains are arranged in a parallel manner and further extended via $\pi-\pi$ aromatic stacking interactions between phen ligands of adjacent chains with centroid-tocentroid distances of $3.633 \AA$ to generate a 2-D layer (Fig. 1b). Then 2-D layers are interconnected into a 3-D H-bond network structure via $\mathrm{C}-\mathrm{H} \cdots \mathrm{Cl}$ and $\mathrm{C}-\mathrm{H} \cdots \mathrm{O} \mathrm{H}$-bonds (Fig. $\mathrm{S} 2 \dagger$ ). The $\mathrm{C} \cdots \mathrm{O}$ distances are in the range of 2.951(6)-3.295(5) $\AA$ and the $\mathrm{C}-\mathrm{H} \cdots \mathrm{O}$ angles are in the range of $123-150^{\circ}$. The $\mathrm{C} \cdots \mathrm{Cl}$ distances vary from $3.686(5)$ to $3.705(6) \AA$ and the $\mathrm{C}-\mathrm{H} \cdots \mathrm{Cl}$ angles vary from 158 to $166^{\circ}$.

Description of $\left[\operatorname{Ln}_{2}(\text { phen })_{2}(\text { glu })_{3}\right]_{n}\{\mathrm{Ln}=\mathrm{Ce}(2 \mathrm{a})$, Tb (2b), Ho (2c)\}. Compounds $\mathbf{2 a - c}$ are isostructural. Therefore, only $\mathbf{2 a}$ is discussed here in detail. 2a crystallizes in the triclinic space group $P \overline{1}$. The asymmetric unit contains two $\mathrm{Ce}^{3+}$ ions, three glu ligands and two phen ligands (Fig. S3†). The coordination geometry of each $\mathrm{Ce}^{3+}$ ion can be described as a distorted capped trigonal antiprism comprised of seven $\mathrm{O}$ atoms of five glu ligands and two $\mathrm{N}$ atoms of phen ligand. The $\mathrm{Ce}-\mathrm{O} / \mathrm{N}$ bond lengths are 2.4208(12)-2.7425(15) A, which are compared with those in other $\mathrm{Ce}^{3+}$ complexes containing carboxylate groups and phen ligands. ${ }^{12}$ There are three crystallographically distinct

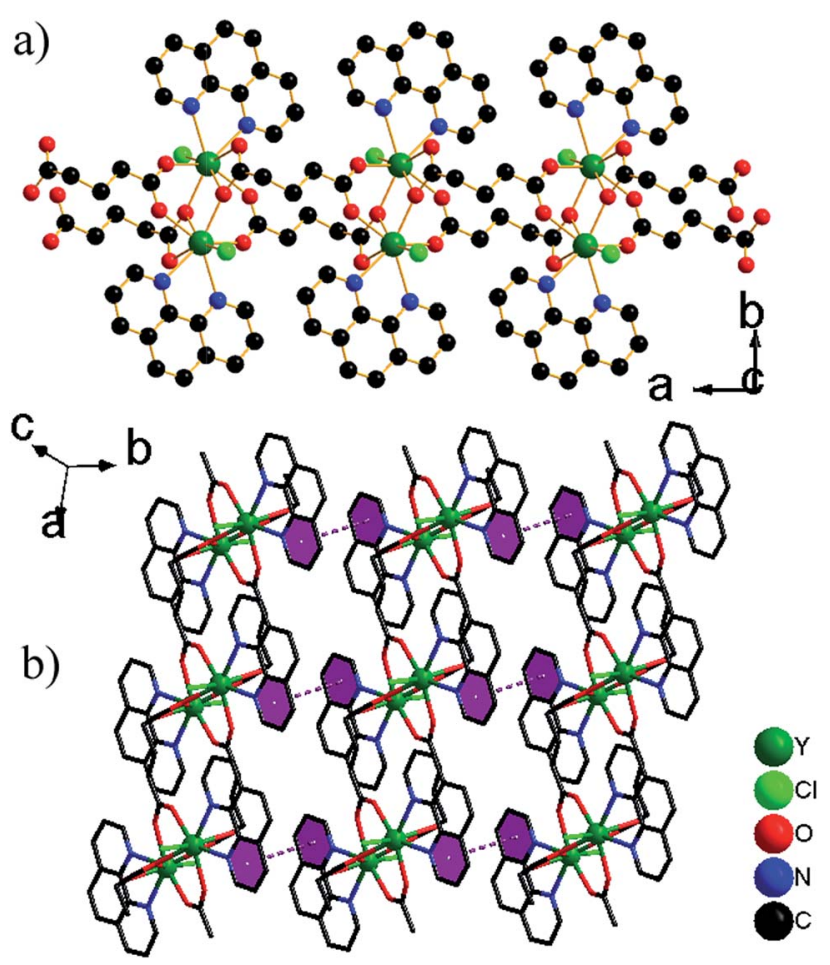

Fig. 1 (a) 1-D chain in 1a. (b) Part of the crystal structure of 1a, showing the formation of a layer constructed by $\pi-\pi$ stacking interactions. $H$ atoms bonded to $\mathrm{C} / \mathrm{N}$ atoms have been omitted for clarity. 

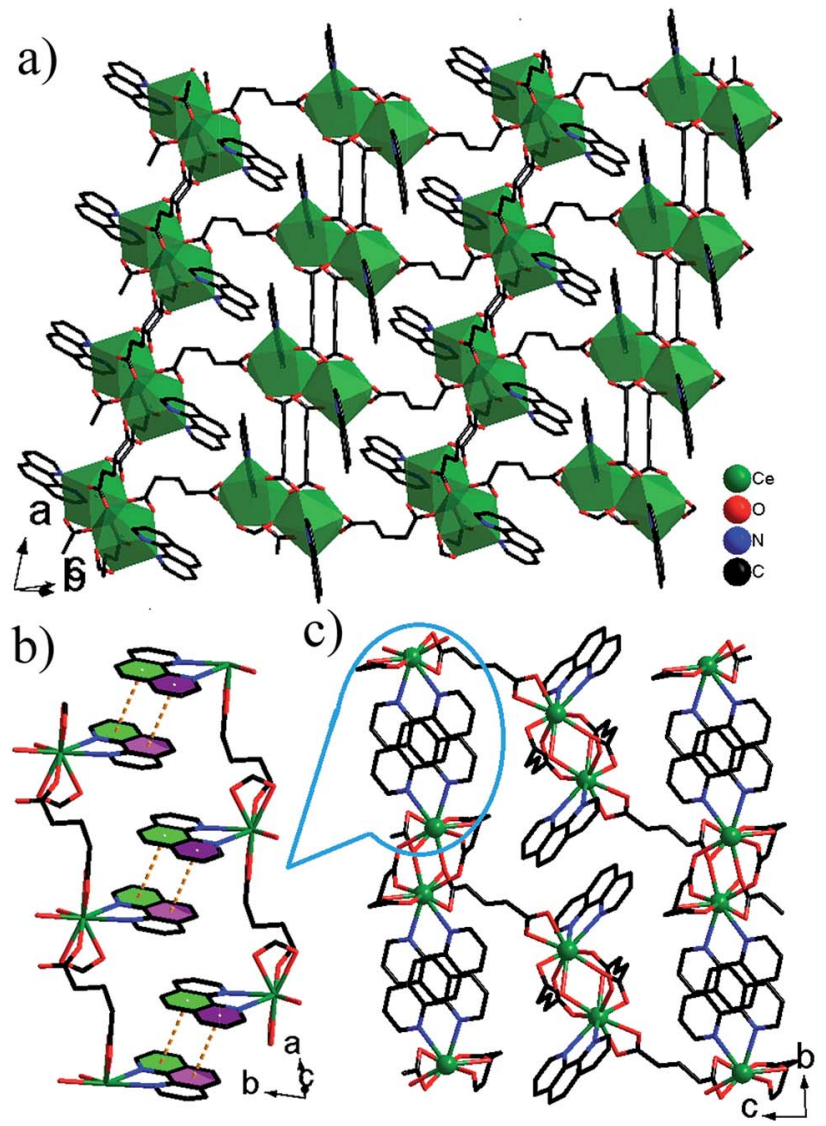

Fig. 2 (a) 2-D layer in 2a. (b) 3-D network structure in 2a. (c) $\pi-\pi$ stacking interactions between phen ligands. $\mathrm{H}$ atoms bonded to $\mathrm{C} / \mathrm{N}$ atoms have been omitted for clarity.

glu ligands, which exhibit two different conformations, namely anti-anti and anti-gauche. One adopts anti-anti conformation, illustrated by the $\mathrm{C} 6-\mathrm{C} 7-\mathrm{C} 8-\mathrm{C} 9\left[178.22(4)^{\circ}\right]$ and $\mathrm{C} 7-\mathrm{C} 8-\mathrm{C} 9-\mathrm{C} 10$ $\left[178.84(4)^{\circ}\right]$ torsion angles, the other adopt the distorted antigauche conformation demonstrated by the $\mathrm{C} 1-\mathrm{C} 2-\mathrm{C} 3-\mathrm{C} 4$ $\left[63.82(6)^{\circ}\right]$ or $\mathrm{C} 11-\mathrm{C} 12-\mathrm{C} 13-\mathrm{C} 14\left[62.48(5)^{\circ}\right]$ torsion angles, and $\mathrm{C} 2-\mathrm{C} 3-\mathrm{C} 4-\mathrm{C} 5\left[172.85(4)^{\circ}\right]$ or $\mathrm{C} 12-\mathrm{C} 13-\mathrm{C} 14-\mathrm{C} 15\left[176.58(4)^{\circ}\right]$ torsion angles, respectively. The $\mathrm{Ce}^{3+}$ ions are grouped in pairs by bridging carboxylate $\mathrm{O}$ atoms. Each pair is connected to four neighbouring pairs via glu ligands, resulting in network of $(4,4)$ topology with the total Schläfli symbol of $4^{4} \cdot 6^{2}$ and the long vertex symbol of $4 \cdot 4 \cdot 4 \cdot 4$ (Fig. 2a). A 3-D network structure is formed by $\pi-\pi$ stacking interactions between phen ligands in the adjacent layers with mean centroid-to-centroid distances of $3.726 \AA$ (Fig. 2b-c).

Description of $\left[\mathrm{La}_{2}(\mathrm{glu})_{3}\left(\mathrm{H}_{2} \mathrm{O}\right)_{3}\right]_{n} \cdot 5 n \mathrm{H}_{2} \mathrm{O}$ (3). Although phen in $\mathbf{3}$ was not incorporated into the final structure, experiments conducted so far show that 3 cannot be synthesized in the absence of phen. So phen played an important role in the formation of 3 , but the mechanism of the reaction is still unclear. 3 crystallizes in the triclinic space group $P \overline{1}$. The asymmetric unit contains two $\mathrm{La}^{3+}$ ions, three glu ligands, three coordinated $\mathrm{H}_{2} \mathrm{O}$ molecules and five free $\mathrm{H}_{2} \mathrm{O}$ molecules (Fig. 3a). The $\mathrm{La}(1)^{3+}$ ion adopts a tetracapped trigonal prism with eight $\mathrm{O}$ atoms of four glu ligands and two $\mathrm{H}_{2} \mathrm{O}$ molecules
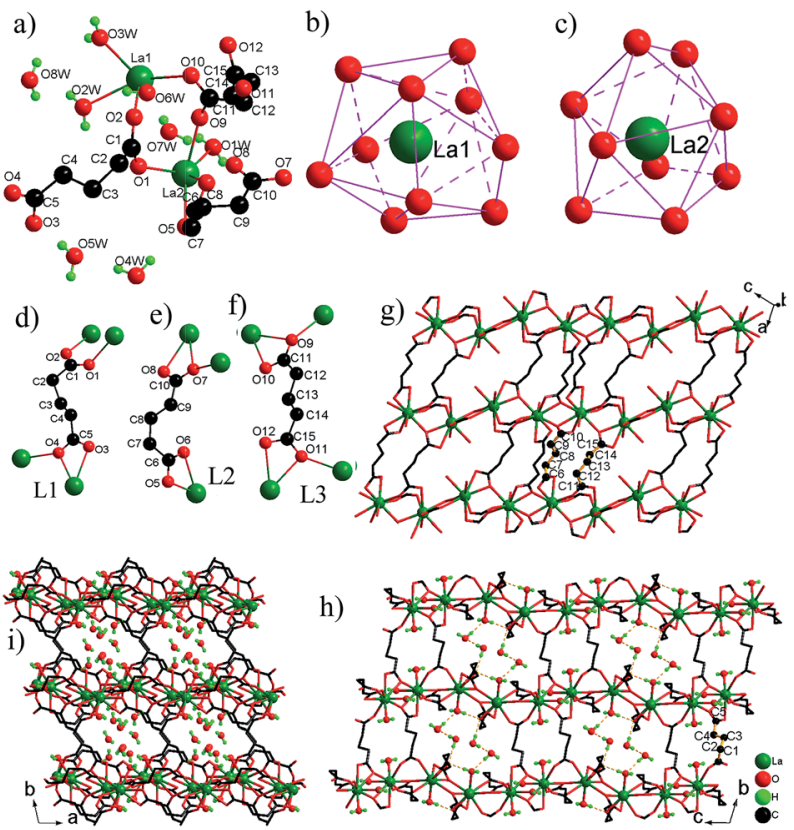

Fig. 3 (a) The asymmetric unit of 3 . ( $b$ and $c$ ) The coordination environments of $\mathrm{La}^{3+}$ ions. (d-f) Coordination modes of glu ligand in 3 . (g) 2-D layer. View of the 3-D framework in 3 along the [100] (h) and [001] (i) directions. $\mathrm{H}$ atoms bonded to $\mathrm{C}$ atoms have been omitted for clarity.

(Fig. 3b), while the $\mathrm{La}(2)^{3+}$ ion adopts a monocapped dodecahedron with eight $\mathrm{O}$ atoms of six glu ligands and one $\mathrm{H}_{2} \mathrm{O}$ molecules (Fig. 3c). The La-O bond distances are in the range

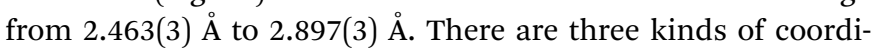
nation modes of glu ligands with the anti-gauche conformation in 3 (Fig. $3 \mathrm{~d}-\mathrm{f}$ ). The first type (L1) is one chelating-anti and one anti-syn $\mathrm{COO}$ ends. The second type (L2) is one chelating and one chelating-anti $\mathrm{COO}$ ends. The third type (L3) is one chelating-anti and one chelating-anti $\mathrm{COO}$ ends. $\mathrm{La}(1)^{3+}$ and $\mathrm{La}^{3+}$ ions are bridged by two -COO groups in the anti-syn mode from two glu ligands and one-COO group in the chelating-anti mode from one glu ligand to $\mathrm{La}_{2}$ dimer with a $\mathrm{La} \cdots \mathrm{La}$ distance of 4.301(1) $\AA$. The $\mathrm{La}_{2}$ dimer units are interconnected via chelating-anti-COO groups to produce a 1-D infinite chain, which is further connected by ligands L2 and L3 into a layer parallel to the (010) plane (Fig. 3g). These layers are pillared by ligand L1 with its chelating-anti-COO group connecting one layer, and its anti-syn -COO group connecting the adjacent layer, leading to a novel 3-D network structure with the 1-D channels occupied by free water molecules (Fig. $3 \mathrm{~h}-\mathrm{i}$ ). There are a lot of $\mathrm{O}-\mathrm{H} \cdots \mathrm{O}$ H-bonds between the coordinated $\mathrm{H}_{2} \mathrm{O}$ molecules and $\mathrm{O}$ atoms of - $\mathrm{COO}$ - groups, which play an important role in stabilizing 3 in the solid state. Moreover, the coordinated $\mathrm{H}_{2} \mathrm{O}$ and free $\mathrm{H}_{2} \mathrm{O}$ molecules interact also by $\mathrm{O}-\mathrm{H} \cdots \mathrm{O}$ H-bonds, resulting in the formation of chain-like $\left(\mathrm{H}_{2} \mathrm{O}\right)_{3}$ unit and $\left(\mathrm{H}_{2} \mathrm{O}\right)_{4}$ ring (Fig. S4 $\dagger$ ), which are retained within the 1-D channels. The $\mathrm{O} \cdots \mathrm{O}$ distances are in the range of 2.746(5)-2.946(5) $\AA$ and the $\mathrm{O}-\mathrm{H} \cdots \mathrm{O}$ angles vary from 143.7 to $177.6^{\circ}$, and are consistent with the values reported in the literature. ${ }^{7}$ 
Although 3-D frameworks of 3 and reported lanthanide glutarates $\left[\mathrm{Ln}(\mathrm{glu})_{3}\left(\mathrm{H}_{2} \mathrm{O}\right)_{2}\right]_{n} \cdot 4 n \mathrm{H}_{2} \mathrm{O}[\mathrm{Ln}=\mathrm{Pr}(\mathbf{4 a}), \mathrm{Nd}(\mathbf{4 b}), \mathrm{Sm}$ (4c), Eu (4d), Gd (4e), Dy (4f), Ho (4g) and Y (4h) $]^{7 a-c}$ are built from $\mathrm{Ln}^{3+}$ ions and glu ligands, the structures are completely different: (a) different 1-D inorganic chains: 1-D chains of $\mathbf{4 a - h}$ is constructed by only type of $\left[\mathrm{LnO}_{8}\left(\mathrm{H}_{2} \mathrm{O}\right)\right]$ polyhedra sharing edge via two -COO group bridges of glu ligands, while 1-D chain of 3 is based on two types of $\left[\mathrm{LaO}_{8}\left(\mathrm{H}_{2} \mathrm{O}\right)_{x}\right](x=1,2)$ polyhedra. (b) Different bridging modes of glu ligands: the structures of $4 \mathbf{a}-$ h possess two types of bridging modes, namely one has two chelating -COO groups, the other has two chelating-anti-COO groups, whereas the structure of $\mathbf{3}$ has three kinds of bridging modes, where two -COO groups of each glu ligand adopt different coordination modes. (c) Different space groups and sizes of channels: 3 crystallizes in space group $P \overline{1}$ and has large rectangular channels that are filled by free water molecules, but $\mathbf{4 a - h}$ crystallizes in space group $C 2 / c$ and has small circular channels, where free water molecules are incorporated.

Influence of lanthanide contraction. Lanthanide contraction is a term used in chemistry to describe the steady decrease in the size of $\mathrm{Ln}^{3+}$ ions with increasing atomic number, where the use of different lanthanide chlorides has dramatically influenced the solid-state architectures of lanthanide glutarates. The reactions of $\mathrm{LnCl}_{3}$ salts and glu ligands in the presence of phen under similar hydrothermal conditions have given two types of lanthanide glutarates. The first type contains a repeating structure unit of the formula $[\mathrm{Ln}(\mathrm{phen})(\mathrm{glu}) \mathrm{Cl}][\mathrm{Ln}=\mathrm{Y}(\mathbf{1 a}), \mathrm{Tm}$ (1b)], where the $\mathrm{Ln}^{3+}$ ions $(\mathrm{Ln}=\mathrm{Y}, \mathrm{Tm})$ all eight-coordinated environment forming the polyhedra $\left[\mathrm{LnO}_{5} \mathrm{~N}_{2}\left(\mathrm{H}_{2} \mathrm{O}\right)\right]$ surrounded by four glu ligands, one phen and one $\mathrm{Cl}^{-}$anion, leading to the 1-D chains. The second type is composed of a repeating molecular composition $\left[\operatorname{Ln}_{2}(\text { phen })_{2}(\mathrm{glu})_{3}\right]\{\mathrm{Ln}=\mathrm{Ce}$ (2a), $\mathrm{Pr}^{8 a} \mathrm{Eu}^{8 a} \mathrm{~Tb}(\mathbf{2 b})$, Ho (2c), $\left.\mathrm{Er}^{8 a}\right\}$, where the coordination number of $\mathrm{Ln}^{3+}$ ions is nine, but each $\mathrm{Ln}^{3+}$ ion is bridged by five glu ligands and one phen, resulting in the 2-D layers. When the above reaction system reacted in the absence of phen, another two types of lanthanide glutarates were obtained. In 3, the coordination number of largest $\mathrm{La}^{3+}$ ion can reach to 10 , and $\mathrm{La}^{3+}$ ion can be surrounded by six glu ligands, but the coordination number of $\mathrm{Ln}^{3+}$ ion in $\left[\mathrm{Ln}(\mathrm{glu})_{3}\left(\mathrm{H}_{2} \mathrm{O}\right)_{2}\right]_{n} \cdot 4 n \mathrm{H}_{2} \mathrm{O}(\mathrm{Ln}=\mathrm{Pr}$, $\mathrm{Nd}, \mathrm{Sm}, \mathrm{Eu}, \mathrm{Gd}, \mathrm{Tb}, \mathrm{Dy}, \mathrm{Ho}$ and $\mathrm{Y})^{7 \boldsymbol{a - c}}$ is nine and each $\mathrm{Ln}^{3+}$ ion is surrounded by five glu ligands. The results demonstrated that the well-known lanthanide contraction has a significant influence on the formation of lanthanide glutarates under hydrothermal conditions.

\section{IR spectra and photoluminescent properties}

The IR spectra of all compounds show the characteristic bands of the $-\mathrm{COO}^{-}$groups in the range of $1627-1517 \mathrm{~cm}^{-1}$ for $v_{\mathrm{C}=\mathrm{O}}$ / $\mathrm{C}-\mathrm{O}$ asymmetric stretching and $1467-1343 \mathrm{~cm}^{-1}$ for $v_{\mathrm{C}=\mathrm{O} / \mathrm{C}-\mathrm{O}}$ symmetric stretching. The weak bands at $3094-3010 \mathrm{~cm}^{-1}$ in 1a-b and 2a-c belong to the $v_{\mathrm{C}-\mathrm{H}}$ stretching of phen ligand, but no similar peaks in 3 appear, which further confirms the absence of phen ligand. The broad band at $3435 \mathrm{~cm}^{-1}$ can be attributed to $v_{\mathrm{O}-\mathrm{H}}$ stretching of water molecules in 3. Upon excitation at $345 \mathrm{~nm}, \mathbf{1 b}$ shows a broad band centered at $388 \mathrm{~nm}$
(Fig. S5 $\dagger$ ). This band is attributed to the ligand emission due to its short lifetime ( $15 \mu$ s obtained from its decay curve). The weak shoulder at $475 \mathrm{~nm}$ is assigned to the transition from the ${ }^{1} \mathrm{G}_{4}$ excited state to the ${ }^{3} \mathrm{H}_{6}$ ground state.

For $\mathbf{2 b}$, the excitation spectrum was obtained by monitoring the most intense emission wavelength of $\mathrm{Tb}^{3+}$ at $545 \mathrm{~nm}$ (Fig. 4a). It shows a broad band ranging from 240 to about $400 \mathrm{~nm}$ attributed to electronic transitions from the ground state level $(\pi) \mathrm{S}_{0}$ to the excited level $\left(\pi^{*}\right) \mathrm{S}_{1}$ of the organic ligand. The excitation spectrum also displays some weak sharp peaks at 326, 369, 378 and $487 \mathrm{~nm}$ assigned to $\mathrm{Tb}^{3+}$ ion intra $\mathrm{f}-\mathrm{f}$ transitions ${ }^{7} \mathrm{~F}_{6} \rightarrow{ }^{5} \mathrm{D}_{1},{ }^{7} \mathrm{~F}_{6} \rightarrow{ }^{5} \mathrm{~L}_{10},{ }^{7} \mathrm{~F}_{6} \rightarrow{ }^{5} \mathrm{G}_{6}$ and ${ }^{7} \mathrm{~F}_{6} \rightarrow{ }^{5} \mathrm{D}_{4}$, respectively. The dominate excitation bands are from the ligand, indicating that a sensitization of $\mathrm{Tb}^{3+}$ luminescence is mainly through an indirect energy transfer process from ligand to $\mathrm{Tb}^{3+}$ ions. Upon excitation at the most intensive wavelength $280 \mathrm{~nm}$ (Fig. 4b), the emission spectrum exhibits four strong emission bands at 489,545, 586, and $622 \mathrm{~nm}$ corresponding to ${ }^{5} \mathrm{D}_{4} \rightarrow{ }^{7} \mathrm{~F}_{\mathrm{J}}(J=6,5,4,3)$, and three weak bands located at 645 , 668 and $679 \mathrm{~nm}$ arising from the ${ }^{5} \mathrm{D}_{4} \rightarrow{ }^{7} \mathrm{~F}_{\mathrm{J}}(J=2,1,0)$, respectively, with the ${ }^{5} \mathrm{D}_{4} \rightarrow{ }^{7} \mathrm{~F}_{5}$ emission as the dominant band. Since no emission bands from the ligand were observed, it is further demonstrated that there is an intramolecular energy transfer from the ligand to $\mathrm{Tb}^{3+}$ ions. The intensities of characteristic $\mathrm{Tb}^{3+}$ emissions are obviously stronger than those of $\left[\mathrm{Tb}\left(\mathrm{H}_{2} \mathrm{O}\right)\right]_{2}(\mathrm{glu})_{3} \cdot 4 \mathrm{H}_{2} \mathrm{O},{ }^{7 c}$ which contain the coordinated $\mathrm{H}_{2} \mathrm{O}$ molecules. This result demonstrated that the introduction of chromophoric phen ligand into the frameworks of lanthanide glutarates can enhance the intensity of $\mathrm{Ln}^{3+}$ emissions. The luminescence decay curve of $\mathrm{Tb}^{3+}$ related to the ${ }^{5} \mathrm{D}_{4} \rightarrow{ }^{7} \mathrm{~F}_{5}$ emission (545 nm) was shown in Fig. 4c. The decay curve is singly exponential, confirming that all $\mathrm{Tb}^{3+}$ ions lie in the same average environment. The luminescence lifetime was determined to be $0.414 \mathrm{~ms}$. The CIE chromaticity coordinate was calculated to be $(0.35,0.59)$, as shown in Fig. $4 \mathrm{~d}$.
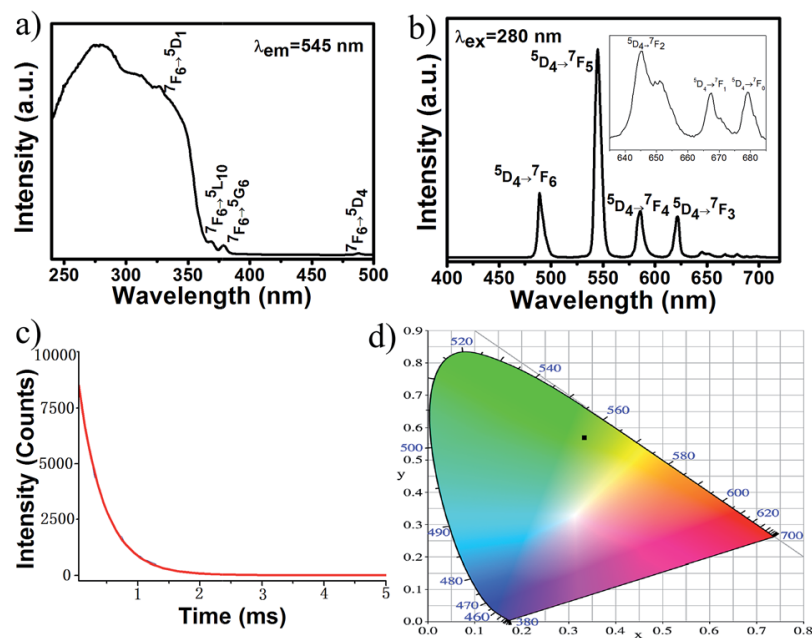

Fig. 4 (a) Excitation spectrum for $2 b\left(\lambda_{e m}=545 \mathrm{~nm}\right)$. (b) Emission spectrum for $2 b$ ( $\lambda_{\text {ex }}=280 \mathrm{~nm}$, the enlarged part shows the emission bands between 635 to $685 \mathrm{~nm}$ ). (c) Decay curve for 2b. (d) ClE chromaticity diagram for $2 \mathrm{~b}$ at $\lambda_{\mathrm{ex}}=280 \mathrm{~nm}$. 


\section{Magnetic properties}

The magnetic susceptibilities of compounds $\mathbf{1 b}, \mathbf{2 b}$ and $2 \mathbf{c}$ were measured in the temperature range $2-300 \mathrm{~K}$ under an applied magnetic field of $1 \mathrm{kOe}$. For $\mathbf{1 b}$, the $\chi_{\mathrm{M}} T$ value $\left(7.37 \mathrm{~cm}^{3} \mathrm{~K}\right.$ $\mathrm{mol}^{-1}$ ) at room temperature is close to the theoretical value for one non-interacting $\mathrm{Tm}^{3+}$ ion $\left(7.08 \mathrm{~cm}^{3} \mathrm{~K} \mathrm{~mol}^{-1}\right.$ for $\mathrm{Tm}^{3+},{ }^{3} \mathrm{H}_{6}, S$ $=1, L=5, J=6, g=7 / 6)$. With lowering temperature, $\chi_{\mathrm{M}} T$ value shows a slight decrease for $\mathbf{1 b}$ (Fig. 5a), as a result of as a consequence of the depopulation of sublevels of the ground $J$ multiplet split by the crystal field ${ }^{\mathbf{1 3}}$ and possible antiferromagnetic interactions. ${ }^{\mathbf{1 4}}$ Antiferromagnetic interactions between $\mathrm{Tm}^{3+}$ ions can be also confirmed by the smaller Tm-O-Tm angle value of $106.97^{\circ}$, because the rule is that $\mathrm{Ln}-\mathrm{O}-\mathrm{Ln}$ angles below $113.50^{\circ}$ are assumed to cause an antiferromagnetic exchange in the literature. ${ }^{15}$ For $2 \mathbf{b}$, the $\chi_{M} T$ value at room temperature is $23.61 \mathrm{~cm}^{3} \mathrm{~K} \mathrm{~mol}^{-1}$ (Fig. 5b), which is in good agreement with the expected theoretical values for two uncoupled $\mathrm{Tb}^{3+}$ ions $\left(23.64 \mathrm{~cm}^{3} \mathrm{~K} \mathrm{~mol}^{-1}\right.$ for $\mathrm{Tb}^{3+},{ }^{7} \mathrm{~F}_{6}, S=3, L=3, J=$ $6, g=3 / 2$ ). Upon cooling, $\chi_{\mathrm{M}} T$ increases to a maximum of 26.33 $\mathrm{cm}^{3} \mathrm{~K} \mathrm{~mol}^{-1}$ at $54 \mathrm{~K}$. This magnetic behavior typifies the ferromagnetic coupling interactions between adjacent $\mathrm{Tb}^{3+}$ centers. A sudden decrease of the $\chi_{M} T$ value below $54 \mathrm{~K}$ suggests that is a consequence of the depopulation of sublevels of the ground $J$ multiplet split by the crystal field and antiferromagnetic interactions. The ferromagnetic interactions provided by chelating-anti -COO bridges ${ }^{2 a}$ in the dimer could also be concomitant with significant antiferromagnetic interactions, due to the $\mathrm{Tb}-\mathrm{O}-\mathrm{Tb}$ angle values in the range of 104.54-107.54 below $113.50^{\circ}$. The classical syn-anti-COO bridges within the dimeric entity appear as the most likely pathways for the antiferromagnetic exchange. ${ }^{2 a}$

For $2 \mathrm{c}$, the $\chi_{\mathrm{M}} T$ value $\left(28.46 \mathrm{~cm}^{3} \mathrm{~K} \mathrm{~mol}^{-1}\right)$ at room temperature (Fig. $5 \mathrm{c}$ ) is as expected for two magnetically isolated $\mathrm{Ho}^{3+}$ ion $\left(28.14 \mathrm{~cm}^{3} \mathrm{~K} \mathrm{~mol}^{-1}\right.$ for $\left.\mathrm{Ho}^{3+},{ }^{5} \mathrm{I}_{8}, S=2, L=6, J=8, g=5 / 4\right)$. As the temperature is lowered, this value remains practically constant until $28 \mathrm{~K}$ and it decreases further to reach a value of $2.46 \mathrm{~cm}^{3} \mathrm{~K} \mathrm{~mol}^{-1}$ at $3 \mathrm{~K}$. This plot can be indicative of the existence of an antiferromagnetic coupling between the $\mathrm{Ho}^{3+}$
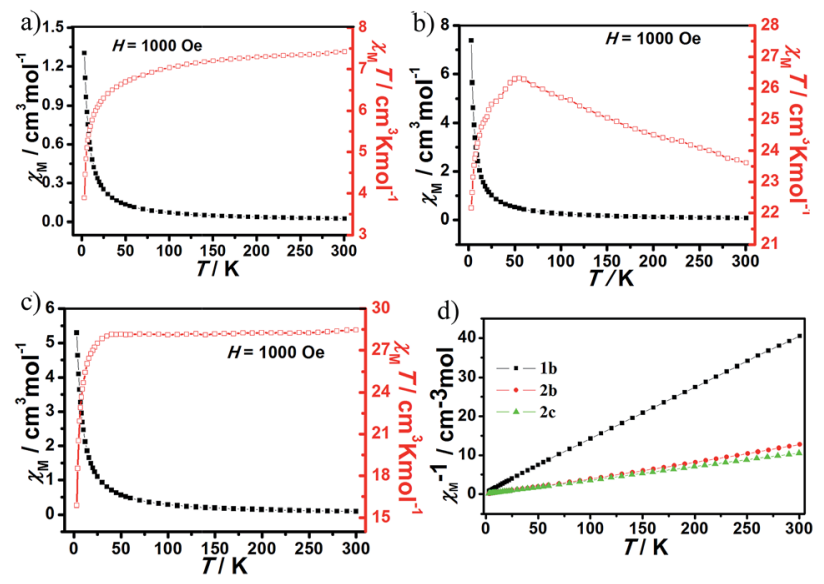

Fig. 5 The plot of $\chi_{M} T$ versus $T$ for $1 b(a), 2 b$ (b) and $2 c$ (c). (d) Plot of $\chi_{M}{ }^{-1}$ versus $T$ for $1 b, 2 b$ and $2 c$. ions, which is further confirmed by the smaller Ho-O-Ho angle values of $103.81-107.58^{\circ}$ below $113.50^{\circ} .{ }^{15}$ The $\chi_{M}{ }^{-1}$ versus $T$ over the entire temperature range for compounds $\mathbf{1 b}, \mathbf{2 b}$ and $2 \mathbf{c}$ can be fitted to the Curie-Weiss law, $\chi_{\mathrm{M}}=C /(T-\theta)$ with the Curie constant $C=7.47,23.95$ and $28.47 \mathrm{~cm}^{3} \mathrm{~K} \mathrm{~mol}^{-1}$, and the Weiss constant $\theta=-4.53,2.65$ and -1.29 , respectively (Fig. 5d).

\section{Conclusions}

A series of lanthanide glutarates were isolated as single crystals under mild hydrothermal conditions in the presence of phen. The lighter $\mathrm{Ln}^{3+}$ ions form the 2-D layers, while the heavier ones form the 1-D chains, where the change in their crystal architectures is obviously related to the well-known lanthanide contraction. The chromophoric phen ligand was incorporated successfully into the frameworks of lanthanide glutarates and prevents water molecules from binding to $\mathrm{Ln}^{3+}$ ions, which could lead to the enhancement of characteristic $\mathrm{Ln}^{3+}$ emissions, for instance, $\mathbf{2 b}$ can emit stronger green luminescence at $545 \mathrm{~nm}$ with long luminescent lifetime, making $2 \mathrm{~b}$ a good candidate for potential green materials. Moreover, the interconnections of $\mathrm{Ln}^{3+}$ ions and glu ligands lead to very robust structural type $\left[\mathrm{Ln}(\mathrm{glu})_{3}\left(\mathrm{H}_{2} \mathrm{O}\right)_{2}\right]_{n} \cdot 4 n \mathrm{H}_{2} \mathrm{O}$, whose $3-\mathrm{D}$ networks containing 1-D inorganic chains of edge-sharing $\left[\mathrm{LnO}_{8}\left(\mathrm{H}_{2} \mathrm{O}\right)\right]$ polyhedra are not changed by different $\mathrm{Ln}^{3+}$ ions, but 3-D framework of 3 contains 1-D inorganic chains based on two types of $\left[\mathrm{LaO}_{8}\left(\mathrm{H}_{2} \mathrm{O}\right)_{x}\right](x=1,2)$ polyhedra, which exhibits a new structural type. The successful synthesis of lanthanide glutarates containing chromophoric phen ligand not only enriches the existing field of lanthanide coordination polymers but also opens possibilities for synthesizing other novel photoluminescent lanthanide glutarates using chromophoric phen derivatives units under desirable conditions.

\section{Acknowledgements}

This work was supported by the NNSF of china (No. 21671029 and 21601038), the NSF of Chongqing municipality (No. cstc2014jcyjA50002, cstc2015jcyjBX0117), Fundação para a Ciência e a Tecnologia (FCT, Portugal), the European Union, QREN, FEDER through Programa Operacional Factores de Competitividade (COMPETE), and CICECO-Aveiro Institute of Materials, POCI-01-0145-FEDER-007679 (FCT Ref. UID/CTM/ 50011/2013), financed by national funds through the FCT/ MEC and when appropriate co-financed by FEDER under the PT2020 Partnership Agreement, and Program for Excellent Talents in Chongqing Higher Education Institutions. The authors are also grateful to Chongqing Normal University for financial support (14CSLJ02), graduate innovative research projects of Chongqing municipality (CYS16147) and the innovative training program of university student (201610637008).

\section{Notes and references}

1 (a) N. Ishikawa, T. Iino and Y. Kaizu, J. Am. Chem. Soc., 2002, 124, 11440; (b) G. Novitchi, W. Wernsdorfer, L. F. Chibotaru, J. Costes, C. E. Anson and A. K. Powell, Angew. Chem., Int. Ed., 
2009, 48, 1614; (c) C. Benelli and D. Gatteschi, Chem. Rev., 2002, 102, 2369; (d) P. Lin, T. J. Burchell, R. Clérac and M. Murugesu, Angew. Chem., Int. Ed., 2008, 47, 8848; (e) J. Peng, X. Kong, Q. Zhang, M. Orendac, J. Prokleska, Y. Ren, L. Long, Z. Zheng and L. Zheng, J. Am. Chem. Soc., 2014, 136, 17938; (f) D. D'Alessio, A. N. Sobolev, B. W. Skelton, R. O. Fuller, R. C. Woodward, N. A. Lengkeek, B. H. Fraser, M. Massi and M. I. Ogden, J. Am. Chem. Soc., 2014, 136, 15122; $(g)$ J. M. Clemente-Juan, E. Coronado and A. Gaita-Arino, Chem. Soc. Rev., 2012, 41, 7464.

2 (a) Y. Zheng, Z. Zheng and X. Chen, Coord. Chem. Rev., 2014, 258-259, 1; (b) P. Zhang, L. Zhang, C. Wang, S. Xue, S. Lin and J. Tang, J. Am. Chem. Soc., 2014, 136, 4484; (c) N. Ishikawa, M. Sugita and W. Wernsdorfer, J. Am. Chem. Soc., 2005, 127, 3650; (d) N. Ishikawa, T. Iino and Y. Kaizu, J. Am. Chem. Soc., 2002, 124, 11440; (e) A. B. Canaj, D. I. Tzimopoulos, M. Siczek, T. Lis, R. Inglis and C. J. Milios, Inorg. Chem., 2015, 54, 7089; (f) X. Tan, J. Zhou, L. Fu, H. Xiao, H. Zou and Q. Tang, Dalton Trans., 2016, 45, 5253.

3 (a) Y. Cui, B. Chen and G. Qian, Coord. Chem. Rev., 2014, 273274, 76; (b) K. Binnemans, Chem. Rev., 2009, 109, 4283; (c) X. Yang, D. Schipper, R. A. Jones, B. J. Holliday, S. Huang and L. A. Lytwak, J. Am. Chem. Soc., 2013, 135, 8468; (d) J. Rausch, V. Lorenz, C. G. Hrib, V. Frettlöh, M. Adlung, C. Wickleder, L. Hilfert, P. G. Jones and F. T. Edelmann, Inorg. Chem., 2014, 53, 11662; (e) X. Feng, Y. Feng, J. J. Chen, S. Ng, L. Wang and J. Guo, Dalton Trans., 2015, 44, 804.

4 (a) G. Stein and E. Wurzberg, J. Chem. Phys., 1975, 62, 208; (b) Y. Haas and G. Stein, J. Phys. Chem., 1971, 75, 3677.

5 (a) L. N. Puntus, K. A. Lyssenko, I. S. Pekareva and J. G. Bünzli, J. Phys. Chem. B, 2009, 113, 9265; (b) R. Martínez-Manez and F. Sancenón, Chem. Rev., 2003, 103, 4419; (c) X. P. Yang, R. A. Jones, M. M. Oye, A. L. Holmes and W.-K. Wong, Cryst. Growth Des., 2006, 6, 2122; (d) J.-C. G. Bünzli and C. Piguet, Chem. Rev., 2002, 102, 1897.

6 (a) X. Huang, Q. Wang, X. Yan, J. Xu, W. Liu, Q. Wang and Y. Tang, J. Phys. Chem. C, 2011, 115, 2332; (b) Y. Hasegawa, S. Tsuruoka, T. Yoshida, H. Kawai and T. Kawai, J. Phys. Chem. A, 2008, 112, 803; (c) P. Lenaerts, A. Storms, J. Mullens, J. D'Haen, C. Görller-Walrand, K. Binnemans and K. Driesen, Chem. Mater., 2005, 17, 5194; (d) X. Ma, X. Li, Y. Cha and L. Jin, Cryst. Growth Des., 2012, 12, 5227; (e) L. N. Puntus, K. A. Lyssenko, M. Y. Antipin and J. G. Bünzli, Inorg. Chem., 2008, 47, 11095.

7 (a) E. Antic-Fidancev, F. Serpaggi and G. Férey, J. Alloys Compd., 2002, 340, 88; (b) F. Serpaggi and G. Férey, J. Mater. Chem., 1998, 8, 2737; (c) B. Yu, C. Xie, X. Wang, R. Wang, G. Shen and D. Shen, J. Coord. Chem., 2007, 60, 1817; (d) C. Wang, Y. Xing, Z. Li, J. Li, X. Zeng, M. Ge and S. Niu, J. Mol. Struct., 2009, 931, 76; (e) P. I. Girginova, F. A. Almeida Paz, P. C. R. Soares-Santos, R. A. Sá Ferreira, L. D. Carlos, V. S. Amaral, J. Klinowski, H. I. S. Nogueira and T. Trindade, Eur. J. Inorg. Chem., 2007, 4238; (f) Y. Kim, Y. Park and D. Jung, Dalton Trans., 2005, 2603; $(g)$ A. Dimos, D. Tsaousis, A. Michaelides, S. Skoulika, S. Golhen, L. Ouahab, C. Didierjean and A. Aubry, Chem. Mater., 2002, 14, 2616.

8 (a) D. Wei, H. Xie, S. Huang, J. Zhou and G. Lu, J. Coord. Chem., 2011, 64, 424; (b) L. Zhang, Y. Wan and L. Jin, J. Mol. Struct., 2003, 646, 169.

9 (a) G. M. Sheldrick, SHELXS-97, Program for the Solution of Crystal Structures, University of Göttingen, Göttingen, Germany, 1997; (b) G. M. Sheldrick, Acta Crystallogr., Sect. A: Found. Crystallogr., 1990, 46, 467.

10 (a) G. M. Sheldrick, SHELXL-97, Program for the Refinement of Crystal Structures, University of Göttingen, Göttingen, Germany, 1997; (b) G. M. Sheldrick, Acta Crystallogr., Sect. A: Found. Crystallogr., 2008, 64, 112.

11 (a) K. P. Carter, S. J. A. Pope and C. L. Cahil, CrystEngComm, 2014, 16, 1873; (b) C. Wang, Z. Wang, F. Gu and G. Guo, J. Mol. Struct., 2010, 979, 92.

12 F. Bai, J. Xu, H. Su and X. Gu, Z. Anorg. Allg. Chem., 2012, 638, 2366.

13 (a) Y.-L. Wang, Y. Ma, X. Yang, J.-K. Tang, P. Cheng, Q.-L. Wang, L.-C. Li and D.-Z. Liao, Inorg. Chem., 2013, 52, 7380; (b) H.-S. Ke, G.-F. Xu, Y.-N. Guo, P. Gamez, C. M. Beavers, S. J. Teat and J.-K. Tang, Chem. Commun., 2010, 46, 6057.

14 (a) G. Abbas, Y. H. Lan, G. E. Kostakis, W. Wernsdorfer, C. E. Anson and A. K. Powell, Inorg. Chem., 2010, 49, 8067; (b) J. Zhou, R. Zhao, T. Yang, X. Liu, H. Xiao, H. Zou and X. Tan, Dalton Trans., 2015, 44, 7203; (c) J. Zhou, H. Xiao, H. Xiao, T. Yang, H. Zou, X. Liu, R. Zhao and Q. Tang, Dalton Trans., 2015, 44, 1350.

15 B. Benmerad, K. Aliouane, N. Rahahlia, A. Guehria-Laïdoudi, S. Dahaoui and C. Lecomte, J. Rare Earths, 2013, 31, 85. 